\title{
Short communication: Inflammation, migration, and cell-cell interaction-related gene network expression in leukocytes is enhanced in Simmental compared with Holstein dairy cows after calving
}

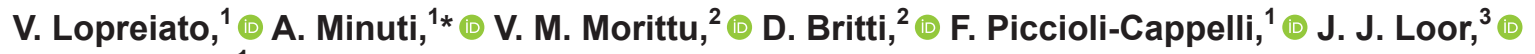 \\ and E. Trevisi ${ }^{1}$ (i) \\ ${ }^{1}$ Department of Animal Sciences, Food and Nutrition, Faculty of Agriculture, Food and Environmental Science, \\ Università Cattolica del Sacro Cuore, 29122 Piacenza, Italy \\ ${ }^{2}$ Interdepartmental Services Centre of Veterinary for Human and Animal Health, Department of Health Science, Magna Græcia University, \\ Catanzaro 88100, Italy \\ ${ }^{3}$ Department of Animal Sciences and Division of Nutritional Sciences, University of Illinois, Urbana 61801
}

\section{ABSTRACT}

The aim of this study was to investigate changes in the abundance of genes involved in leukocyte function between cows highly specialized for milk production (Holstein, $\mathrm{n}=12$ ) and cows selected for meat and milk (Simmental, $\mathrm{n}=13$ ). Blood was collected on $\mathrm{d}$ 3 after calving in PAXgene tubes (Preanalytix, Hombrechtikon, Switzerland) to measure mRNA abundance of 33 genes. Normalized gene abundance data were subjected to MIXED model ANOVA using SAS (SAS Institute Inc. Cary, NC). Simmental cows had greater transcript abundance of proinflammatory cytokines and receptor genes (IL1B, TNF, IL1R, TNFRSF1A), cell migration- and adhesion-related genes (CX3CR1, ITGB2, CD44, LGALS8), and the antimicrobial IDO1 gene. In contrast, compared with Holstein cows, Simmental cows had lower abundance of the toll-like receptor (TLR) recognition-related gene TLR2, the antimicrobial-related gene $L T F$, and $S 100 A 8$, which is involved in cell maturation, regulation of inflammatory processes, and immune response. These results revealed that breed plays an important role in the modulation of genes involved in immune adaptation and inflammatory response, and the immune system of Simmental cows could potentially have a more acute response in early lactation. In turn, this might be beneficial for mounting a more efficient response after calving and allow for a smoother homeorhetic adaptation to lactation.

Key words: PAXgene, Simmental, leukocytes, transition period

Received July 19, 2019.

Accepted October 21, 2019.

*Corresponding author: andrea.minuti@unicatt.it

\section{Short Communication}

Simmental is a cattle breed selected for meat and milk production, which, during the last decades in intensive production systems, has undergone intense selection for higher milk yield while still maintaining the dual-purpose characteristic. The different features in Simmental (selected for both milk and beef production traits) and Holstein cows (selected for milk traits) are due to distinct genetic patterns and breeding histories, which has led to the hypothesis that innate and adaptive immune responses differ between these breeds when managed under an intensive dairy production system with similar environmental or experimental conditions. For instance, whole-blood transcriptome analysis revealed that Simmental and Holstein cows have similar patterns but varying degrees of activation of metabolic and physiological mechanisms associated with environmental adaptation. In fact, compared with Simmental cows, Holsteins had a greater number of affected genes and impacted pathways, suggesting differences in metabolic activity (Sandri et al., 2015; Pošćić et al., 2017). However, no previous studies have attempted to investigate differences in abundance of genes involved in immune adaptations and inflammatory responses between these breeds immediately after calving.

Polymorphonuclear leukocyte cells (PMNL) and lymphocyte functions decrease gradually starting about 2 wk before calving, with the lowest degree of responsiveness between time of calving and $2 \mathrm{~d}$ afterward (Kehrli et al., 1989; Batistel et al., 2018). This dysfunction encompasses reduced activity of the superoxide production, phagocytosis, and expression of cell surface adhesion molecules, as well as a reduction of capacity for migration (Kehrli et al., 1989; Burton et al., 1995, 2005). According to Kehrli et al. (1989), impaired 
neutrophil function during the periparturient period is primarily attributable to the hormonal and metabolic changes that prepare the mammary gland for lactation. In fact, around this critical period, metabolism of dairy cows shifts from the demands of pregnancy to those of lactation. Notably, most studies on impairment of innate and adaptive immune functions during the transition period have been undertaken using highyielding dairy cows. Hence, the objective of the present study was to explore gene network profiles of 33 genes involved in recognition, immune mediation, migration, cell adhesion, antimicrobial mechanisms, the inflammatory cascade, oxidative stress, and the leukotriene pathway in leukocytes from Simmental and Holstein cows immediately after calving. We hypothesized that leukocyte function and response would differ between cows highly specialized for milk production such as Holstein and dual-purpose cows selected for meat and milk production such as Simmental.

The trial was carried out in accordance with Italian laws on animal experimentation (DL n. 26, 04/03/2014) and ethics (Authorization of Italian Health Ministry N 403/2017-PR). The experimental design of this study involved 13 Simmental and 12 Holstein cows representing the control group from a larger cohort. Details of management, diet, health status, and metabolic status of cows have been published previously (Lopreiato et al., 2019). Briefly, management procedures for Simmental and Holstein cows were similar: cows were fed once daily (0700 and $0800 \mathrm{~h}$, lactating and dry cows, respectively) with a TMR, and after parturition were milked twice daily (at 0500 and $1700 \mathrm{~h}$ ). On d 3 after calving, blood was sampled $(2.5 \mathrm{~mL})$ from the jugular vein into PAXgene Blood RNA System tubes (Preanalytix, Hombrechtikon, Switzerland) for RNA extraction. The use of PAXgene tubes in cattle has been reported previously (Sandri et al., 2015; Pošćić et al., 2017).

The complete procedure for RNA extraction from PAXgene RNA tubes was performed according to the manufacturer's protocol (Blood RNA Kit Handbook, PreAnalitix GmbH, Qiagen, Hilden, Germany). Complete details of the procedure are presented in Supplemental File S1 (https://doi.org/10.3168/jds.2019 -17298). After extraction, RNA was quantified using the Qubit RNA BR Assay Kit (Invitrogen, Thermo Fisher Scientific, Waltham, MA), and RNA quality was assessed with the Experion Automated Electrophoresis System (Bio-Rad, Hercules, CA). The average $( \pm S D)$ RNA quality index was $9 \pm 0.52$. All samples used in the analysis were diluted with nuclease-free water to a concentration of $100 \mathrm{ng}$ of $\mathrm{RNA} / \mu \mathrm{L}$, and synthesis of cDNA was performed using a reverse transcription kit (RevertAid RT Reverse Transcription Kit; Thermo
Fisher Scientific). The qPCR was performed using $4 \mu \mathrm{L}$ of diluted cDNA combined with $6 \mu \mathrm{L}$ of mixture composed of $5 \mu \mathrm{L} 1 \times$ SYBR Green Master Mix (Applied Biosystems, Woolston Warrington, UK), $0.4 \mu \mathrm{L}$ each of $10 \mu \mathrm{M}$ forward and reverse primers, and $0.2 \mu \mathrm{L}$ of nuclease-free water. Three replicates were run for each sample. The qPCR efficiency and quantification cycle values were obtained for each reaction using LinRegPCR (Version 2017.1; Amsterdam UMC, Amsterdam, the Netherlands). The final data were normalized using the geometric mean of 3 internal control genes: $A C T B$, $S D H A$, and YWHAZ. Additional details are reported in Supplemental File S1 (https://doi.org/10.3168/jds .2019-17298). Normalized gene abundance data were analyzed using the MIXED procedure of SAS version 9.4 (SAS Institute Inc., Cary, NC), in which the fixed effect was breed, and cows were included as random effect. All means were compared using the PDIFF statement of SAS. Significant differences were declared at $P \leq 0.05$.

The abundance of genes investigated for leukocyte functions in Simmental and Holstein dairy cows is presented in Table 1. Compared with Holstein, Simmental dairy cows had greater $(P \leq 0.05)$ transcript abundance of the proinflammatory cytokines $I L 1 B$ and $T N F$, the cytokine receptors $I L 1 R$ and TNFRSF1A, the cell migration-related gene $C X 3 C R 1$, the cell adhesionrelated genes ITGB2, CD44, and LGALS8, and the cell antimicrobial-related gene IDO1. In contrast, Holstein cows had greater $(P<0.05)$ abundance of the toll-like receptor (TLR) recognition-related gene TLR2, the antimicrobial-related gene $L T F$, and $S 100 A 8$, which is involved in cell maturation, regulation of inflammatory processes, and immune response.

Directed migration to inflammatory sites is an important function of PMNL but also of monocytes and lymphocytes. Chemokine receptors are pivotal for chemotaxis, and chemokine signaling is essential for immune cell migration during bacterial infection (Sallusto and Baggiolini, 2008). The CX3CR1 protein is the receptor for CX3CL1, also known as fractalkine. According to several studies, CX3CR1 is expressed by monocytes, macrophages, dendritic cells, $\mathrm{T}$ cells, and natural killer cells; depending on environmental condition, its interaction with CX3CL1 mediates chemotaxis of immune cells in either a pro- or an anti-inflammatory response (Lee et al., 2018).

Previous studies with Holstein cows reported downregulation of chemokine and chemokine-receptor genes after calving (Seo et al., 2013; Crookenden et al., 2016), confirming that homeorhetic adaptations after parturition are associated with a reduction of leukocyte responsiveness and migration to inflammatory sites. 
The fact that abundance of $C X 3 C R 1$ was greater in Simmental leukocytes after parturition may be indicative of a greater migration capacity of leukocytes (chemotaxis).

Leukocyte adhesion and transmigration across the endothelial barrier represent a process that is a consequence of a combined action involving cytokines and chemoattractants. The adhesion of leukocytes is guaranteed by the expression of selectins, which bind to adhesion molecules located on the surface of endothelial cells near the inflamed tissues (Kansas, 1993). In addition, CD44 was identified as one of the 3 endothelial-selectin (E-selectin) ligands on PMNL, which causes the leukocytes to slow down, activating rolling of PMNL, and then their extravasation during inflam- mation (Hidalgo et al., 2007). After selectins allow for binding between leukocytes and endothelial cells, $\beta 2$ integrins interact with intercellular adhesion molecules, thereby attaching more firmly with endothelial cells (Engelhardt and Wolburg, 2004). Thus, these latter molecules allow leukocytes to leave blood circulation to act as phagocytes at the site of inflammation (Taooka et al., 1999).

Compared with those of Holsteins, the upregulation of $L G L A S 8$ in Simmental leukocytes could reflect a difference in neutrophil migration and phagocytic capacity between these breeds. In fact, LGALS8 (Galectin-8) is involved in cell-extracellular matrix adhesion (reversible), which plays an important role in the migration of neutrophils into target tissues (Zick et al., 2002; Nishi

Table 1. Normalized arbitrary mRNA abundance of genes involved in leukocyte function from Simmental or Holstein dairy cows at $3 \mathrm{~d}$ after calving, grouped according to primary function

\begin{tabular}{|c|c|c|c|c|}
\hline \multirow[b]{2}{*}{ Target } & \multicolumn{2}{|c|}{ Breed } & \multirow[b]{2}{*}{$\mathrm{SEM}^{1}$} & \multirow[b]{2}{*}{$P$-value } \\
\hline & Holstein & Simmental & & \\
\hline \multicolumn{5}{|c|}{ Recognition and immune mediation } \\
\hline CD14 & 72.94 & 63.09 & 3.76 & 0.38 \\
\hline$C D 16$ & 88.38 & 115.40 & 15.90 & 0.10 \\
\hline$M Y D 88$ & 145.46 & 171.05 & 13.83 & 0.07 \\
\hline$T L R 2$ & 44.70 & 39.09 & 2.65 & 0.04 \\
\hline \multicolumn{5}{|c|}{ Migration and adhesion } \\
\hline CCR2 & 34.85 & 39.23 & 3.87 & 0.26 \\
\hline$C X 3 C R 1$ & 18.19 & 26.72 & 3.09 & 0.01 \\
\hline$I T G B 2$ & 182.94 & 223.05 & 16.25 & 0.02 \\
\hline ITGAL & 45.72 & 53.99 & 4.98 & 0.11 \\
\hline TLN1 & 256.30 & 276.70 & 20.35 & 0.32 \\
\hline SELL & 500.96 & 544.13 & 33.01 & 0.20 \\
\hline$S E L P L G$ & 236.77 & 298.35 & 31.86 & 0.06 \\
\hline$C D 44$ & 163.76 & 214.77 & 9.75 & $<0.01$ \\
\hline$L G A L S 8$ & 36.20 & 45.28 & 2.65 & $<0.01$ \\
\hline IL8 & 26.65 & 17.46 & 2.47 & 0.14 \\
\hline \multicolumn{5}{|c|}{ Antimicrobial strategies } \\
\hline$M M P 9$ & 73.69 & 41.13 & 3.97 & 0.10 \\
\hline LTF & 3.72 & 0.68 & 0.44 & 0.04 \\
\hline$M P O$ & 2.58 & 4.19 & 0.87 & 0.07 \\
\hline LCN2 & 23.59 & 16.13 & 3.48 & 0.43 \\
\hline IDO1 & 33.28 & 58.17 & 5.70 & 0.03 \\
\hline \multicolumn{5}{|c|}{ Inflammatory cascade } \\
\hline$C A S P 1$ & 27.37 & 28.04 & 2.43 & 0.78 \\
\hline TNFRSF1A & 209.39 & 248.15 & 20.22 & 0.05 \\
\hline$T N F$ & 9.96 & 12.06 & 0.73 & $<0.01$ \\
\hline IL1B & 64.60 & 117.64 & 18.73 & $<0.01$ \\
\hline$I L 1 R$ & 26.69 & 31.86 & 2.10 & 0.02 \\
\hline$I R A K 1$ & 43.40 & 42.65 & 2.56 & 0.77 \\
\hline IL18 & 9.22 & 10.83 & 1.04 & 0.13 \\
\hline NLRP3 & 29.47 & 31.85 & 0.71 & 0.31 \\
\hline S100A8 & 936.47 & 586.68 & 181.27 & 0.06 \\
\hline RPL13A & 986.24 & 1175.07 & 111.98 & 0.10 \\
\hline \multicolumn{5}{|c|}{ Leukotrienes and oxidative status } \\
\hline$A L O X 5$ & 15.87 & 23.13 & 1.57 & 0.10 \\
\hline$A L O X 15$ & 27.64 & 38.24 & 6.75 & 0.12 \\
\hline SOD1 & 59.40 & 62.57 & 5.00 & 0.52 \\
\hline SOD2 & 164.32 & 217.22 & 13.98 & 0.18 \\
\hline
\end{tabular}

${ }^{1}$ Greatest SEM. 
et al., 2003). Additionally, LGALS8 has been described as a receptor with the ability to activate intracellular bacterial killing (Thurston et al., 2012), a feature indicating that downregulation of $L G A L S 8$ may reduce not only the capacity of neutrophils to migrate into target tissues but also the ability of neutrophils to kill pathogens.

Together, the upregulation of ITGB2, CD44, $C X$ C3CR1, and LGALS8 after calving suggests that leukocytes in Simmental cows possess a greater degree of functionality, thereby contributing to a lower incidence of infection postpartum (greater influx of leukocytes into tissues). Furthermore, the upregulation of adhesion and migration molecules in Simmental cows was likely associated with the greater abundance of cytokine- and cytokine receptor-related genes (IL1B, IL1R, TNF, TNFRSF1A), functioning as checkpoint regulators of leukocyte recruitment, trafficking, and maturation during the inflammatory response (Schmidt et al., 2013; Heiser et al., 2018).

The proinflammatory cytokines IL- $1 \beta$ and TNF- $\alpha$ are characterized by similar biological effects on the host innate immune response to infection, including activation of endothelial cells and leukocytes (Bannerman, 2009). The protein encoded by the IDO1 gene (indolamine 2,3-dioxygenase) is involved in the first step of tryptophan degradation through the kynurenine pathway. The antimicrobial mechanism generated by IDO1 induction is characterized by the reduction of tryptophan availability for pathogen growth at the infected site, and its activity is stimulated by proinflammatory cytokines (Mellor, 2005). Our findings on IDO1 are consistent with the abundance of genes involved in the inflammatory cascade, which imply an enhanced inflammatory mediation in Simmental cows to support the innate and adaptive immune response.

A relevant relationship between immune response and metabolic adaptation after calving should be emphasized. In particular, during the first month after calving, metabolic data of cows involved in this study indicated that Simmental had significantly lower levels of BHB and free fatty acids compared with Holstein cows (Lopreiato et al., 2019). In vivo and in vitro experiments have revealed that leukocyte functions such as chemotaxis, phagocytosis, and superoxide anion release are reduced by high levels of BHB in circulation (Sartorelli et al., 1999, 2000; Suriyasathaporn et al., 1999). A recent study by Crookenden et al. (2019) highlighted the negative effects of high circulating free fatty acids, BHB, and liver triacylglycerol after calving on mRNA abundance of neutrophil function genes. Results indicated that cows with elevated levels of these biomarkers (defined as "high-risk" cows) were characterized by downregulation of genes involved in recruitment, migration, and interferon signaling, suggesting that neutrophil inflammatory mediation may not be as efficient in high-risk cows as in low-risk cows. This underscores the pivotal role of the negative energy balance (NEB) in the innate and adaptive immune response after calving (Hammon et al., 2006).

In particular, among the genes investigated, Holstein leukocytes had greater mRNA abundance of TLR2. Toll-like receptors are expressed in immune cells such as neutrophils and macrophages, recognizing pathogenassociated molecular patterns on invading pathogens (Kumar et al., 2011). On the basis of our results, that Simmental leukocytes had upregulation of pro-inflammatory genes, this outcome was unexpected because TLR play a major role in inducing innate immunity and activating the pro-inflammatory response (Kumar et al., 2011). Moyes et al. (2010) highlighted the upregulation of mRNA abundance of TLR2 and TLR 4 in circulating PMNL during an intramammary infection with Streptococcus uberis in Holstein dairy cows experiencing NEB compared with cows in positive energy balance. Thus, the increased amount of saturated fatty acids that occurs during postpartal NEB via adipocyte lipolysis (Douglas et al., 2007) may act as ligands for TLR, as reported previously in human macrophage cell lines (Lee et al., 2001, 2003). This could explain the upregulation of TLR2 in Holstein cows, which had greater free fatty acid levels after calving than Simmental cows. Clearly, the relationship between lipids and immune response is not well understood, and further studies are needed to elucidate this aspect. Thus, NEB could be a key to understanding differences in leukocyte function between the 2 breeds investigated herein, because Simmental cows were also characterized by a lower milk production compared with Holsteins (Lopreiato et al., 2019).

Further efforts should be addressed to ascertain that, when different breeds are compared for innate and adaptive immune response during the transition period, other breed-specific mechanisms are involved. Data reported in the present study provide evidence of unique expression markers immediately after parturition between immune cells of Simmental cows (a dual-purpose breed for milk and meat production) and Holstein cows (a breed specialized for milk production). Hence, breed could play an important role in the modulation of those genes involved in immune adaptation and inflammatory response. However, further investigation should be focused on temporal changes to determine whether differences pointed out herein are still observed before parturition and over the first or second week after parturition. 


\section{ACKNOWLEDGMENTS}

This project was financially supported by the Department of Animal Sciences, Food and Nutrition (DIANA, Faculty of Agriculture, Food and Environmental Science; Università Cattolica del Sacro Cuore, Piacenza, Italy), by the Interdepartmental Services Centre of Veterinary for Human and Animal Health (Magna Graecia University, Catanzaro, Italy), and by the Romeo ed Enrica Invernizzi Foundation (Milan, Italy). The authors declare no conflicts of interest.

\section{REFERENCES}

Bannerman, D. D. 2009. Pathogen-dependent induction of cytokines and other soluble inflammatory mediators during intramammary infection of dairy cows. J. Anim. Sci. 87(Suppl. 13):10-25. https:/ /doi.org/10.2527/jas.2008-1187.

Batistel, F., J. M. Arroyo, C. I. M. Garces, E. Trevisi, C. Parys, M. A. Ballou, F. C. Cardoso, and J. J. Loor. 2018. Ethyl-cellulose rumen-protected methionine alleviates inflammation and oxidative stress and improves neutrophil function during the periparturient period and early lactation in Holstein dairy cows. J. Dairy Sci. 101:480-490. https://doi.org/10.3168/jds.2017-13185.

Burton, J. L., M. E. Kehrli Jr., S. Kapil, and R. L. Horst. 1995. Regulation of L-selectin and CD18 on bovine neutrophils by glucocorticoids: Effects of cortisol and dexamethasone. J. Leukoc. Biol. 57:317-325. https://doi.org/10.1002/jlb.57.2.317.

Burton, J. L., S. A. Madsen, L.-C. Chang, P. S. D. Weber, K. R. Buckham, R. van Dorp, M.-C. Hickey, and B. Earley. 2005. Gene expression signatures in neutrophils exposed to glucocorticoids: A new paradigm to help explain "neutrophil dysfunction" in parturient dairy cows. Vet. Immunol. Immunopathol. 105:197-219. https: //doi.org/10.1016/j.vetimm.2005.02.012.

Crookenden, M. A., A. Heiser, A. Murray, V. S. R. Dukkipati, J. K. Kay, J. J. Loor, S. Meier, M. D. Mitchell, K. M. Moyes, C. G. Walker, and J. R. Roche. 2016. Parturition in dairy cows temporarily alters the expression of genes in circulating neutrophils. J. Dairy Sci. 99:6470-6483. https://doi.org/10.3168/jds.2015-10877.

Crookenden, M. A., K. M. Moyes, B. Kuhn-Sherlock, K. Lehnert, C. G. Walker, J. J. Loor, M. D. Mitchell, A. Murray, V. S. R. Dukkipati, M. Vailati-Riboni, A. Heiser, and J. R. Roche. 2019. Transcriptomic analysis of circulating neutrophils in metabolically stressed peripartal grazing dairy cows. J. Dairy Sci. 102:7408-7420. https:/ /doi.org/10.3168/jds.2019-16367.

Douglas, G. N., J. Rehage, A. D. Beaulieu, A. O. Bahaa, and J. K. Drackley. 2007. Prepartum nutrition alters fatty acid composition in plasma, adipose tissue, and liver lipids of periparturient dairy cows. J. Dairy Sci. 90:2941-2959. https://doi.org/10.3168/jds.2006 -225 .

Engelhardt, B., and H. Wolburg. 2004. Mini review: Transendothelial migration of leukocytes: Through the front door or around the side of the house? Eur. J. Immunol. 34:2955-2963. https://doi.org/10 $.1002 /$ eji.200425327.

Hammon, D. S., I. M. Evjen, T. R. Dhiman, J. P. Goff, and J. L. Walters. 2006. Neutrophil function and energy status in Holstein cows with uterine health disorders. Vet. Immunol. Immunopathol. 113:21-29. https://doi.org/10.1016/j.vetimm.2006.03.022.

Heiser, A., S. J. LeBlanc, and S. McDougall. 2018. Pegbovigrastim treatment affects gene expression in neutrophils of pasture-fed, periparturient cows. J. Dairy Sci. 101:8194-8207. https://doi.org/ 10.3168/jds.2017-14129.

Hidalgo, A., A. J. Peired, M. K. Wild, D. Vestweber, and P. S. Frenette. 2007. Complete identification of E-selectin ligands on neutrophils reveals distinct functions of PSGL-1, ESL-1, and CD44. Immunity 26:477-489. https://doi.org/10.1016/j.immuni.2007.03 .011 .
Kansas, G. S. 1993. Regulation of leukocyte rolling and adhesion to high endothelial venules through the cytoplasmic domain of Lselectin. J. Exp. Med. 177:833-838. https://doi.org/10.1084/jem .177 .3 .833

Kehrli, M. E., B. J. Nonnecke, and J. A. Roth. 1989. Alterations in bovine neutrophil function during the periparturient period Am. J. Vet. Res. 50:207-214. https://doi.org/10.1016/S0261 $-5177(02) 00005-5$.

Kumar, H., T. Kawai, and S. Akira. 2011. Pathogen recognition by the innate immune system. Int. Rev. Immunol. 30:16-34. https://doi .org/10.3109/08830185.2010.529976.

Lee, J. Y., A. Plakidas, W. H. Lee, A. Heikkinen, P. Chanmugam, G. Bray, and D. H. Hwang. 2003. Differential modulation of Toll-like receptors by fatty acids. J. Lipid Res. 44:479-486. https://doi.org/ 10.1194/jlr.M200361-JLR200.

Lee, J. Y., K. H. Sohn, S. H. Rhee, and D. Hwang. 2001. Saturated fatty acids, but not unsaturated fatty acids, induce the expression of cyclooxygenase-2 mediated through Toll-like receptor 4 . J. Biol. Chem. 276:16683-16689. https://doi.org/10.1074/jbc M011695200.

Lee, M., Y. Lee, J. Song, J. Lee, and S.-Y. Chang. 2018. Tissue-specific role of CX 3 CR 1 expressing immune cells and their relationships with human disease. Immune Netw. 18:e5. https://doi.org/ 10.4110/in.2018.18.e5.

Lopreiato, V., A. Minuti, F. Trimboli, D. Britti, V. M. Morittu, F. P. Cappelli, J. J. Loor, and E. Trevisi. 2019. Immunometabolic status and productive performance differences between periparturient Simmental and Holstein dairy cows in response to pegbovigrastim. J. Dairy Sci. 102:9312-9327. https://doi.org/10.3168/jds .2019-16323.

Mellor, A. 2005. Indoleamine 2,3 dioxygenase and regulation of $\mathrm{T}$ cell immunity. Biochem. Biophys. Res. Commun. 338:20-24. https:// doi.org/10.1016/j.bbrc.2005.08.232.

Moyes, K. M., J. K. Drackley, D. E. Morin, and J. J. Loor. 2010. Greater expression of TLR2, TLR4, and IL6 due to negative energy balance is associated with lower expression of HLA-DRA and HLA-A in bovine blood neutrophils after intramammary mastitis challenge with Streptococcus uberis. Funct. Integr. Genomics 10:53-61. https://doi.org/10.1007/s10142-009-0154-7.

Nishi, N., H. Shoji, M. Seki, A. Itoh, H. Miyanaka, K. Yuube, M. Hirashima, and T. Nakamura. 2003. Galectin-8 modulates neutrophil function via interaction with integrin M. Glycobiology 13:755-763. https://doi.org/10.1093/glycob/cwg102.

Pošćić, N., T. Montanari, M. D'Andrea, D. Licastro, F. Pilla, P. Ajmone-Marsan, A. Minuti, and S. Sgorlon. 2017. Breed and adaptive response modulate bovine peripheral blood cells' transcriptome. J. Anim. Sci. Biotechnol. 8:11. https://doi.org/10.1186/ s40104-017-0143-y.

Sallusto, F., and M. Baggiolini. 2008. Chemokines and leukocyte traffic. Nat. Immunol. 9:949-952. https://doi.org/10.1038/ni.f.214.

Sandri, M., B. Stefanon, and J. J. Loor. 2015. Transcriptome profiles of whole blood in Italian Holstein and Italian Simmental lactating cows diverging for genetic merit for milk protein. J. Dairy Sci. 98:6119-6127. https://doi.org/10.3168/jds.2014-9049.

Sartorelli, P., S. Paltrinieri, and F. Agnes. 1999. Non-specific immunity and ketone bodies. I: In vitro studies on chemotaxis and phagocytosis in ovine neutrophils. J. Vet. Med. Ser. A Physiol. Pathol. Clin. Med. 46:613-619. https://doi.org/10.1046/j.1439-0442.1999 $.00252 . \mathrm{x}$.

Sartorelli, P., S. Paltrinieri, and S. Comazzi. 2000. Non-specific immunity and ketone bodies. II: In vitro studies on adherence and superoxide anion production in ovine neutrophils. J. Vet. Med. Ser. A Physiol. Pathol. Clin. Med. 47:1-8. https://doi.org/10.1046/j .1439-0442.2000.00253.x.

Schmidt, S., M. Moser, and M. Sperandio. 2013. The molecular basis of leukocyte recruitment and its deficiencies. Mol. Immunol 55:49-58. https://doi.org/10.1016/j.molimm.2012.11.006.

Seo, J., J. S. Osorio, and J. J. Loor. 2013. Purinergic signaling gene network expression in bovine polymorphonuclear neutrophils during the peripartal period. J. Dairy Sci. 96:7675-7683. https://doi .org/10.3168/jds.2013-6952. 
Suriyasathaporn, W., A. J. Daemen, E. N. Noordhuizen-Stassen, S. J. Dieleman, M. Nielen, and Y. H. Schukken. 1999. Beta-hydroxybutyrate levels in peripheral blood and ketone bodies supplemented in culture media affect the in vitro chemotaxis of bovine leukocytes. Vet. Immunol. Immunopathol. 68:177-186. https://doi.org/ 10.1016/S0165-2427(99)00017-3.

Taooka, Y., J. Chen, T. Yednock, and D. Sheppard. 1999. The integrin

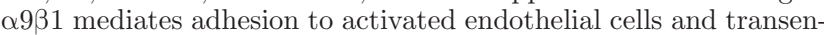
dothelial neutrophil migration through interaction with vascular cell adhesion molecule-1. J. Cell Biol. 145:413-420. https://doi .org/10.1083/jcb.145.2.413.

Thurston, T. L. M., M. P. Wandel, N. von Muhlinen, Á. Foeglein, and F. Randow. 2012. Galectin 8 targets damaged vesicles for autophagy to defend cells against bacterial invasion. Nature 482:414-418. https://doi.org/10.1038/nature10744.

Zick, Y., M. Eisenstein, R. A. Goren, Y. R. Hadari, Y. Levy, and D. Ronen. 2002. Role of galectin-8 as a modulator of cell adhesion and cell growth. Glycoconj. J. 19:517-526. https://doi.org/10.1023/B: GLYC.0000014081.55445.af.

\section{ORCIDS}

V. Lopreiato ํ https://orcid.org/0000-0001-6965-7340

A. Minuti (1) https://orcid.org/0000-0002-0617-6571

V. M. Morittu @ https://orcid.org/0000-0001-6790-5734

D. Britti @ https://orcid.org/0000-0001-7355-8791

F. Piccioli-Cappelli @ https://orcid.org/0000-0003-1277-7821

J. J. Loor ๑ https://orcid.org/0000-0003-1586-4365

E. Trevisi (ㄴ https://orcid.org/0000-0003-1644-1911 